\title{
FAILURE INVESTIGATION OF AXLE BOX SPRING OF RAILWAY 16T COACHES
}

\author{
Rohan Joshi ${ }^{1}$, Sachin Chaudhari ${ }^{2}$, Dhanraj Choudhari ${ }^{3}$, Pratik Chaugule ${ }^{4}$ \\ ${ }^{1} U G$ Student, Department of Mechanical Engineering, ZE'S DCOER, Narhe, Pune, \\ Maharashtra, India \\ ${ }^{2} U G$ Student, Department of Mechanical Engineering, ZE'S DCOER, Narhe, Pune, \\ Maharashtra, India \\ ${ }^{3} U G$ Student, Department of Mechanical Engineering, ZE'S DCOER, Narhe, Pune, \\ ,Maharashtra, India \\ ${ }^{4} U G$ Student, Department of Mechanical Engineering, ZE'S DCOER, Narhe, Pune, \\ Maharashtra, India
}

\begin{abstract}
Spring is an elastic member whose main function is to deflect or distort under load and to recover its original shape when load is removed. The springs used in the bogie suspension of Railway coaches are helical compression springs. Visual examination shows that failure is common between first to third coils. The exact time of failure cannot be determined as the coaches come for POH after 18 months. Some cracks also negotiate during load testing. Pattern of cracks showing it may subject to transverse forces. The cracks are detected in Magnaflux testing. The present works attempt to analyze design of primary suspension springs used in Railway coaches under transverse loading while negotiating curved path by using ANSYS 14.5 software. Stresses induced are compared with allowable stresses. Typical 16T coaches have been considered for the failure analysis.
\end{abstract}

Keywords: Helical compression springs, load \& stress calculation, POH, ANSYS 14.5, Modeling, Primary Suspension system, axle box spring, Bolster spring, Creo 2.0.

\section{INTRODUCTION}

Indian Railways plays a key role in transportation of goods and passengers across India. As part of our contribution we have taken up a project related to Indian Railways. Indian Railway has vast maintenance regarding to coaches. Every coach after working for 18 months comes for $\mathrm{POH}$. This project will involve creating a solid model of the helical spring using Creo software with the given Specifications and analyzing the same model by using ANSYS 14.5 software, under transverse loading. Behavior of the spring is observed for different material for particular loading. Particular 16T coaches have been selected for analysis. Each Coach has two bogies with 2 axles each. A bogie with 2 axles is shown in fig 1 . Suspension of bogie consists of primary and secondary suspension system. Springs used for primary suspension is known as axle box spring while for secondary is known as bolster spring.[1] Total 16 axle box spring and 8 bolster springs are used. Suspension is provided in car body for:

1) Better riding comfort

2) Improved reliability and reduced maintenance

3) Capacity to sustain super dense crush load . Most common cause of spring failure is the fatigue fracture, which is due to imperfections present in the material or due to crack formation during service. $* * *$

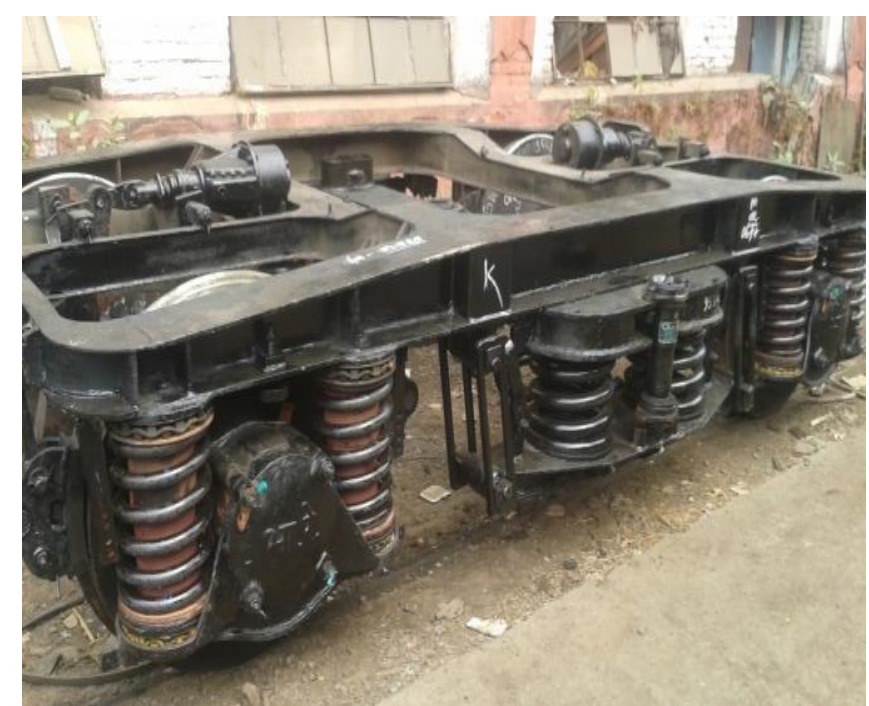

Fig 1.Bogie with primary and secondary suspension system

\subsection{Observations}

During POH every spring undergone for magnaflux testing. The internal cracks developed are generally not visible to human eye. Fig 2. Shows the cracks detected during maganaflux testing. Area undergoing cracks shows there is a shear failure, but there are some cracks are found which also shows that transverse area is also subjected to shear failure. From that it is concluded that springs are may subjected to transverse loading. Transverse forces are produced while moving on curved path. 

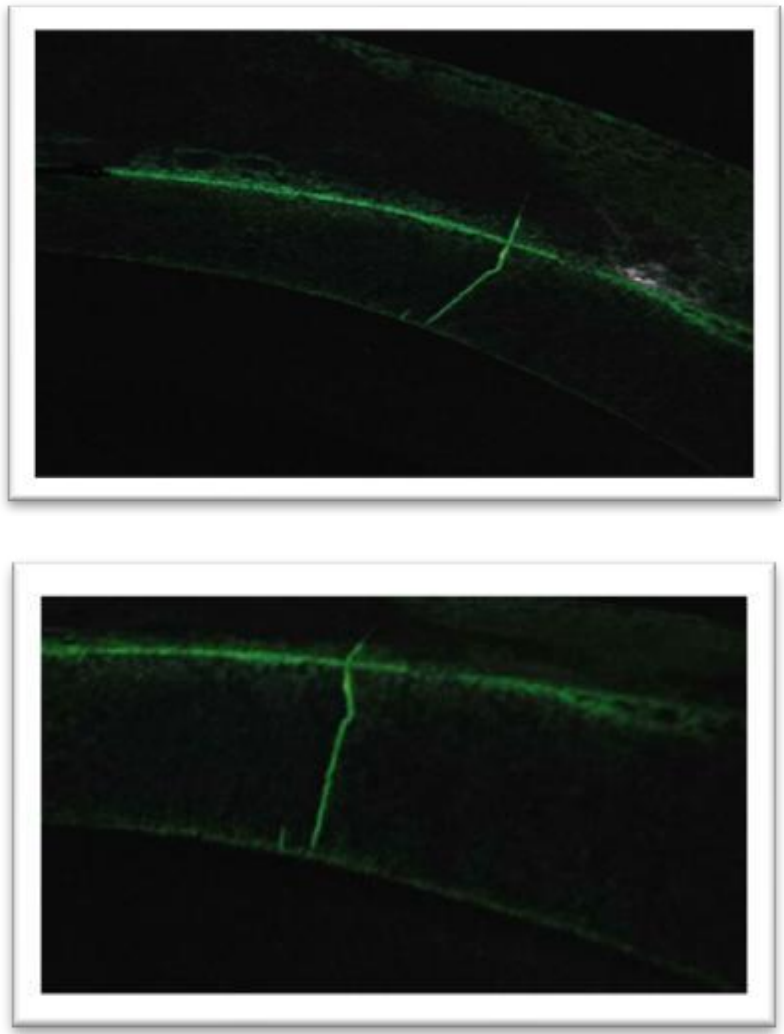

Fig 2 Results of magnaflux testing

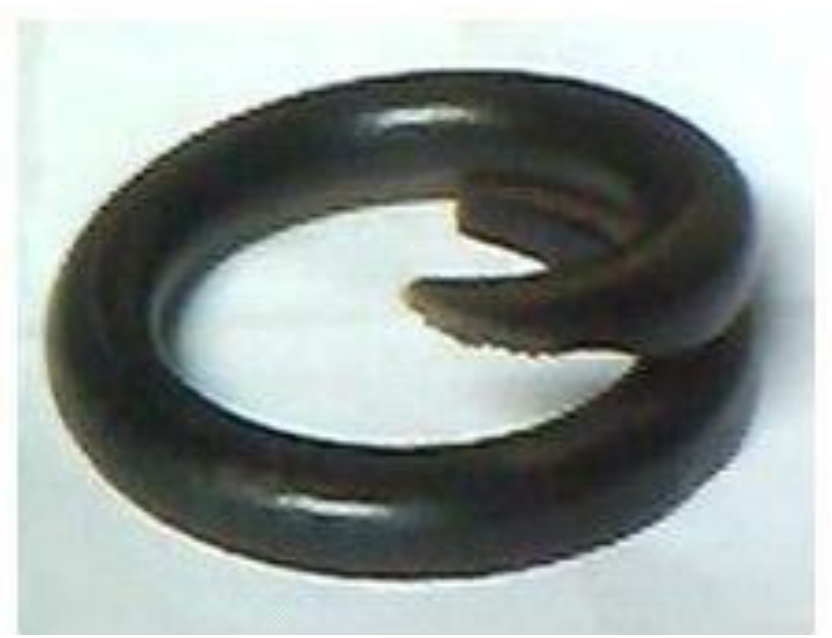

Fig 3 Actual failed coil spring

\section{METHODOLOGY}

A static analysis calculates the effects of steady loading conditions on a structure, while ignoring inertia and damping effects, such as those caused by time-varying loads. These are the helical spring used to absorb shock and vibration coming on the wheels of coaches. This paper tries to check the design of spring while moving on curved and straight path. Bogie structure is such that the net sprung mass is first taken by bolster spring. Bolster plate is main component while considering load analysis. Bolster springs are fitted between bolster plate. As it takes the load first and transfers sprung mass to suspension spring. Bolster spring first deform by $25 \mathrm{~mm}$ and then remaining load is transferred to axle box spring[3]. Bolster plate is not welded to the bogie it is a floating component. When train moves over curved path it freely floats but still axle box spring is subjected to transverse loading as shown in fig 2 . It is necessary to check the design for such loading. Material used for axle box spring is Chrome-Vanadium i.e. $52 \mathrm{Cr} 4 \mathrm{Mo} 2 \mathrm{~V}$. The technical specifications of Primary spring (Axle box spring) are shown in table 1[2]. Axle box guides are of cylindrical type welded to the bottom flanges of the bogie side frame with close dimensional accuracy. These guides together with lower spring seats located over the axle box wings which house the axle box springs and also serve as shock absorbers.

Table 1: Technical Specification of Spring

\begin{tabular}{|l|l|l|}
\hline Particulars & Unit & $\begin{array}{l}\text { Axle box } \\
\text { spring }\end{array}$ \\
\hline Free height & $\mathrm{mm}$ & 375 \\
\hline Wire diameter & $\mathrm{mm}$ & 33.5 \\
\hline Outer diameter & $\mathrm{mm}$ & 242 \\
\hline Inner diameter & $\mathrm{mm}$ & 175 \\
\hline No. of effective coils & - & 5.25 \\
\hline Total no. of coils & - & 6.75 \\
\hline Deflection under $1000 \mathrm{~kg}$ & $\mathrm{~mm}$ & 37.07 \\
\hline Shear stress /1000 $\mathrm{kgf}$ & $\mathrm{kg} / \mathrm{cm}^{2}$ & 1412 \\
\hline Pitch & $\mathrm{mm}$ & 65.21 \\
\hline Modulus of rigidity & $\mathrm{Kg} / \mathrm{cm}^{2}$ & 8155 \\
\hline Young's Modulus & $\mathrm{Pa}$ & $2.068 \mathrm{E}+11$ \\
\hline Density & $\mathrm{kg} / \mathrm{m}^{3}$ & 7833.4 \\
\hline
\end{tabular}

\section{LOAD ANALYSIS FOR COACH}

\subsection{For Straight Path}

Following assumptions were made for simplification i)The rails are smooth and there are no geometrical irregularities.

ii) The loading is static. iii) Impact load during operation are neglected. The overall load of about 46.2 tonne of coach with payload is acted over the suspension springs on all wheel set. Using various load acted upon the axle assembly when loco is moving on straight path are as given below 1) Total weight of loco $=46.2 \mathrm{~T} 2$ ) Unsprung mass per bogie $=$ $3.984 \mathrm{~T}$ 3) Total unsprung mass $=7.968 \mathrm{~T} 4$ ) Net load on all axles $=39.8 \mathrm{~T} 5$ ) This net load is distributed over each of frontal and rear wheel sets through front and rear wheel frames.

Thus net load distributed on each frame $=19.9 \mathrm{~T}$.[4]

At first this load of $19.9 \mathrm{~T}$ is acted over each secondary coil spring as the height of this spring is $25 \mathrm{~mm}$ more than all the primary spring.[8] For $25 \mathrm{~mm}$ of deflection each spring will carry 11555 N. Hence net load on each Primary spring is $12416 \mathrm{~N}$. 


\subsection{For Curved Path}

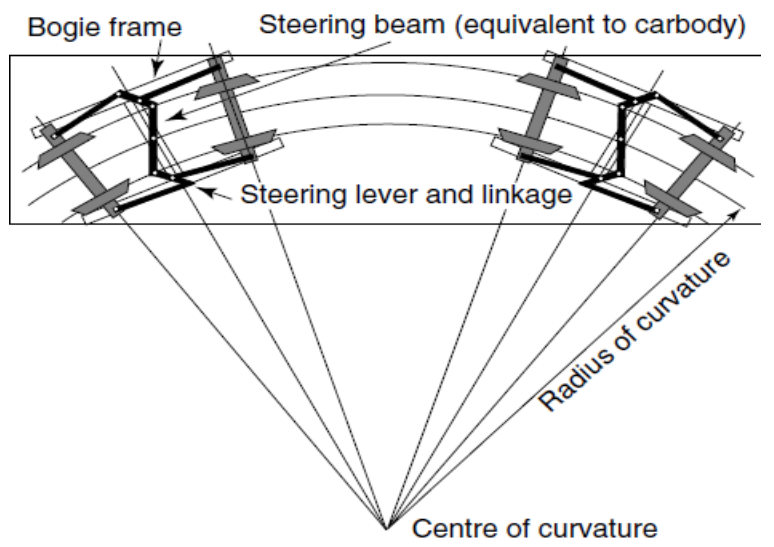

Fig 4 Path of vehicle on curved path

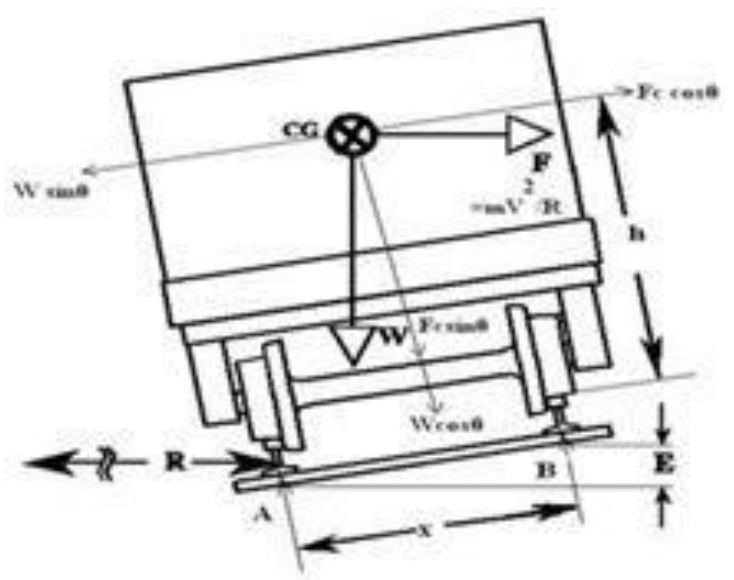

Fig 5 Component of forces while moving on curved path.[8]

To negotiate curves on the railway track, only the bolster spring are given the free play in a lateral direction perpendicular to the direction of motion. It should be noted that the axle do not turn about the loco but there is a sliding of the bolster plate which helps in negotiating the curve. While moving on the curved path the loco is subjected to additional lateral load because of centrifugal force which causes the lateral load on the spring with its bending moment maximum at the top end.

1) The loco speed is $54 \mathrm{~km} / \mathrm{hr}$.

2) The radius of curvature is $194 \mathrm{~m}$, which is the minimum recommended radius.

3) The banking angle is $9^{0}$.[5]

4) Diameter of wheel is $1016 \mathrm{~mm}$.

5) Centrifugal force, $F_{c}=2857 \mathrm{~N}$.

\section{MODELING OF HELICAL SPRING}

This spring has square and ground end. Based on this analysis, design recommendations will be made. A Model of the spring will be first created design using Creo software. For modelling of helical spring different steps are followed and begin by drawing a line of $375 \mathrm{~mm}$ length. This is the free height of the spring. Pitch of the spring is entered which is $65.21 \mathrm{~mm}$, create the circle of wire Diameter $33.5 \mathrm{~mm}$ of spring and generate spring. Spring is generated by using double helical sweep as it is difficult to draw the end coil which has different pitch and a cut section for rectangular cross section. The solid model of coil spring end steps as shown in fig 4.

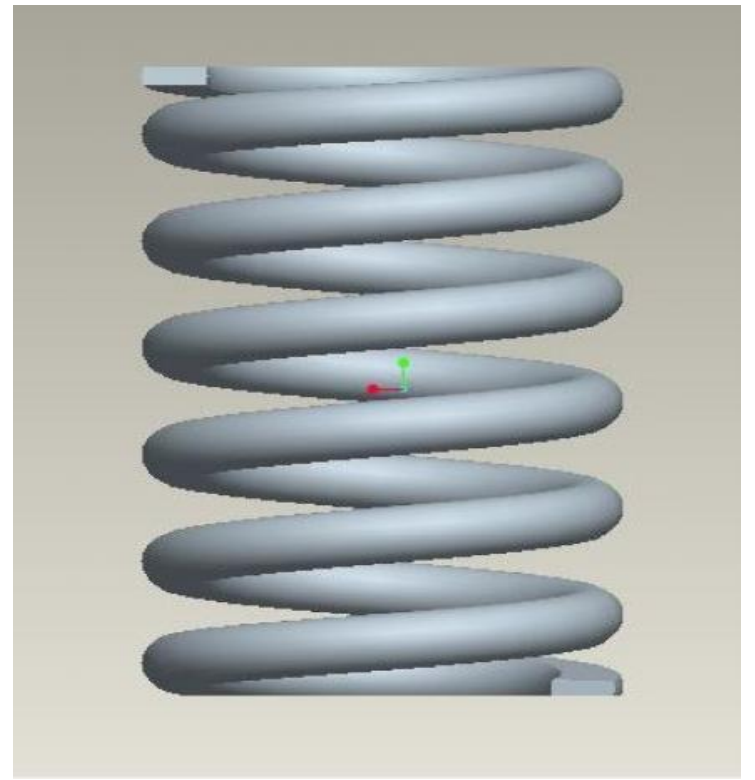

Fig 6 Actual 3D model of spring in Creo

\section{FE ANALYSIS OF PRIMARY SPRING}

Using the technical specification of spring the FE analysis was carried out in ANSYS 14.5 software. The analysis was carried out for both the above mentioned loading cases. For the analysis purpose the plate with higher rigidity was mounted on the top and below the spring for axial loading and fixing up the displacement. Modal created in Creo is imported in ANSYS. Meshing is an important procedure in $\mathrm{FE}$ analysis. Meshing is a discretization process in which component is converted into number of small elements of defined size. Tetrahedrons meshing method is used. The deflection and maximum shear stresses are obtained which will compare with the results calculated.[6]. The figure depicts the loading and boundary condition for each of the cases. The FE analysis of spring at straight path is shown in figure and at curved path is shown in figure .

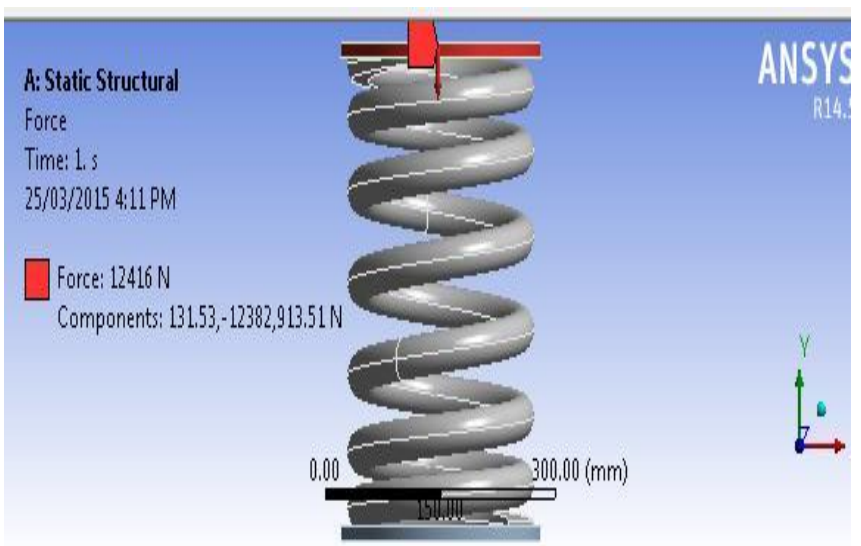

Fig 7 Loading \& boundary condition for spring at straight path with vertical loading 


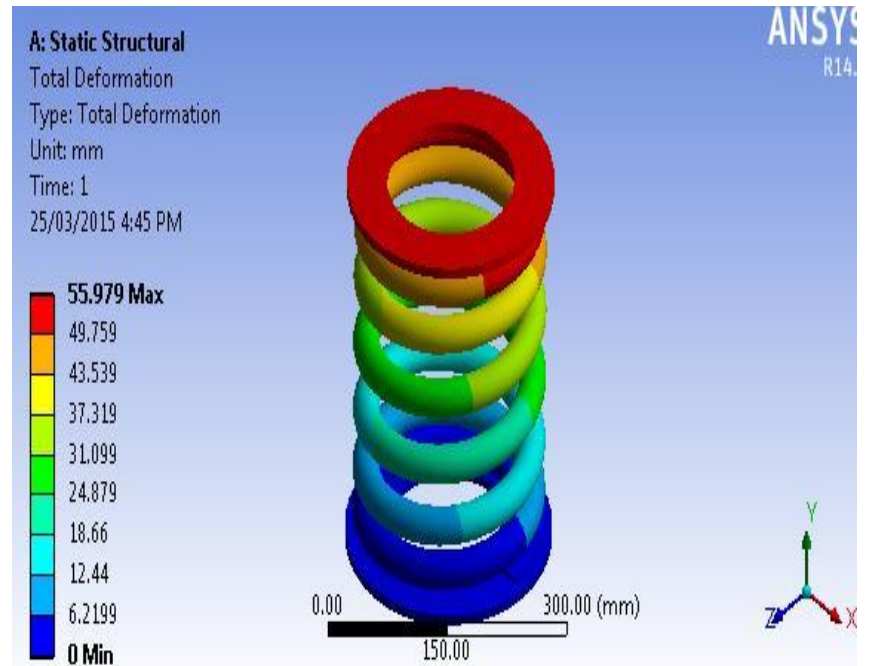

Fig 8 maximum deflection $=55.97 \mathrm{~mm}$ at straight path

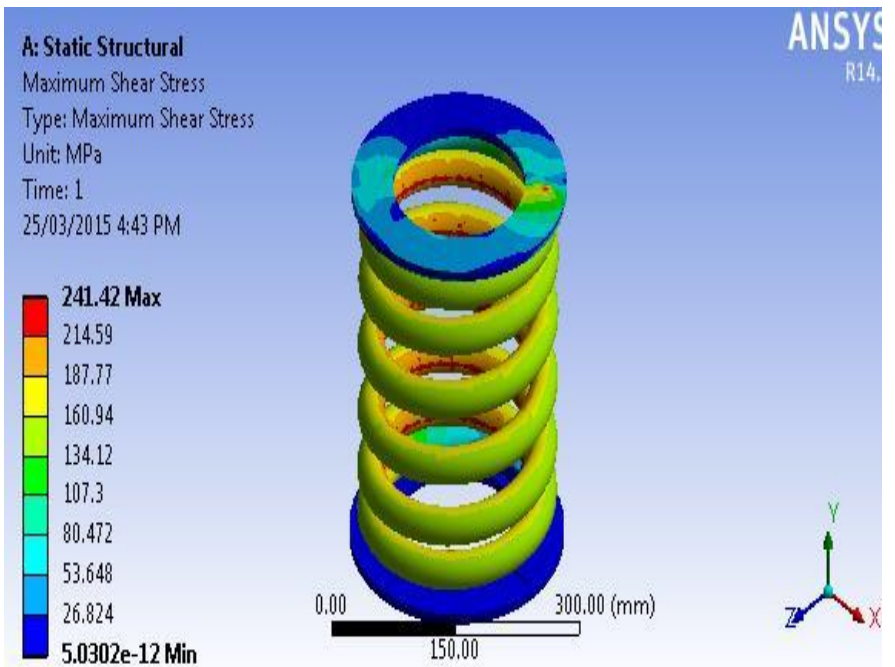

Fig 9 maximum shear stress $=241 \mathrm{~N} / \mathrm{mm} 2$

Table 2

\begin{tabular}{|l|ll|l|l|l|l|}
\cline { 3 - 6 } \multicolumn{2}{c|}{} & \multicolumn{3}{|l|}{ ANALYTICAL } & FEA \\
\hline CONDITION & $\begin{array}{l}\text { LOAD } \\
(\mathrm{N})\end{array}$ & $\begin{array}{l}\text { SHEAR } \\
\text { STRESS } \\
\left(\mathrm{N} / \mathrm{mm}^{2}\right)\end{array}$ & $\begin{array}{l}\text { DEFORMATION } \\
(\mathrm{mm})\end{array}$ & $\begin{array}{l}\text { SHEAR } \\
\text { STRESS } \\
\left(\mathrm{N} / \mathrm{mm}^{2}\right)\end{array}$ & $\begin{array}{l}\text { DEFORMATION } \\
(\mathrm{mm})\end{array}$ \\
\hline STRAIGHT PATH & 12416 & 218 & 47 & 241 & 55.97 \\
\hline CURVED PATH & $\begin{array}{l}2857 \\
12716\end{array}$ & - & - & 1318 & 69.25 \\
\hline
\end{tabular}

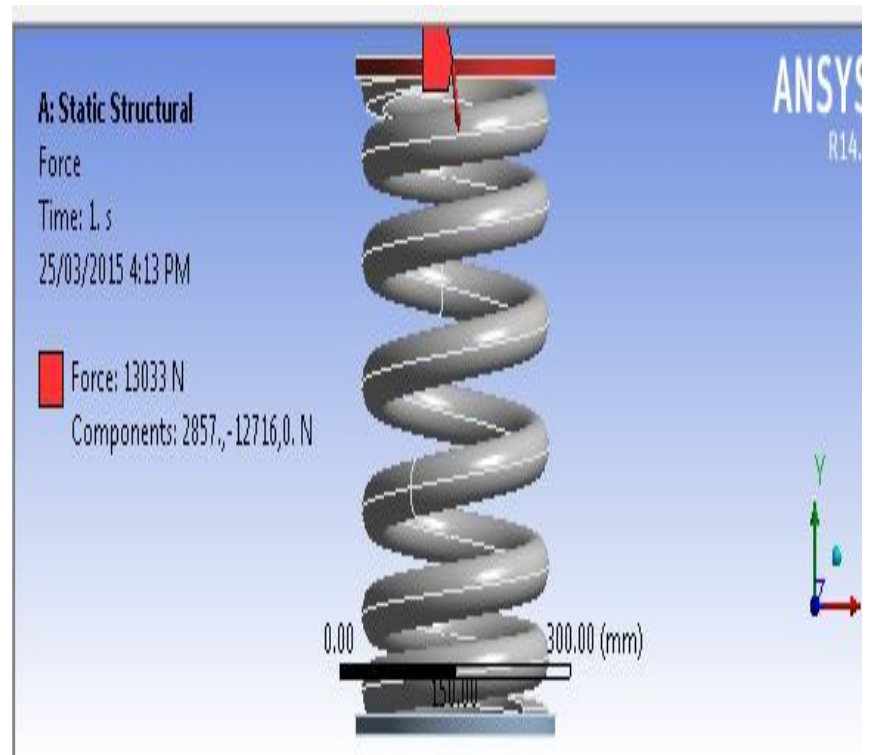

Fig 10 Loading \& boundary condition for spring at curvature with vertical and lateral loading

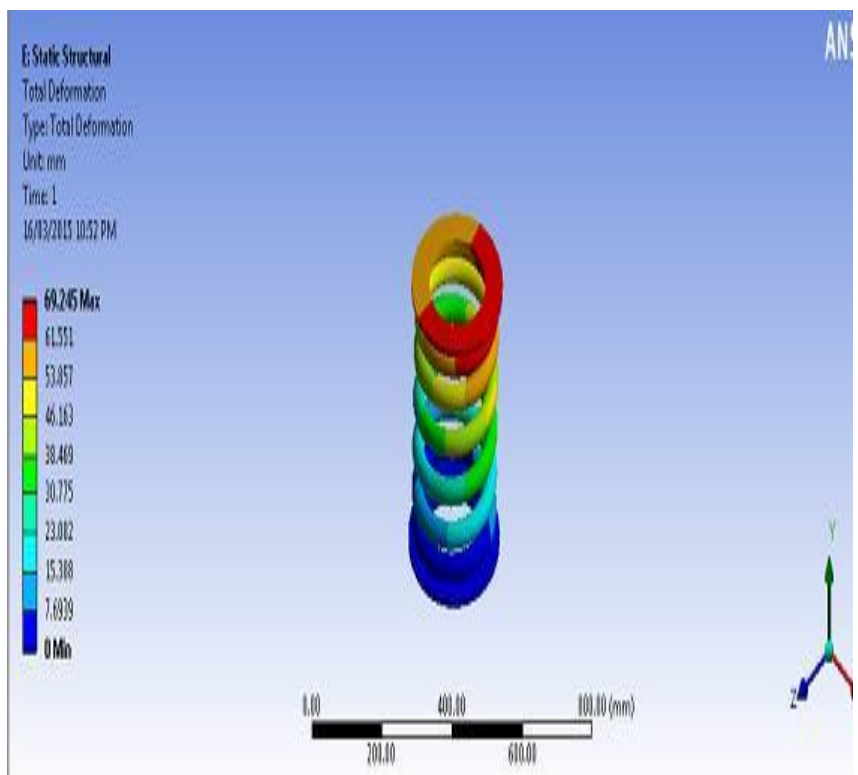

Fig 11 maximum deflection=69.25 $\mathrm{mm}$ at curved path 


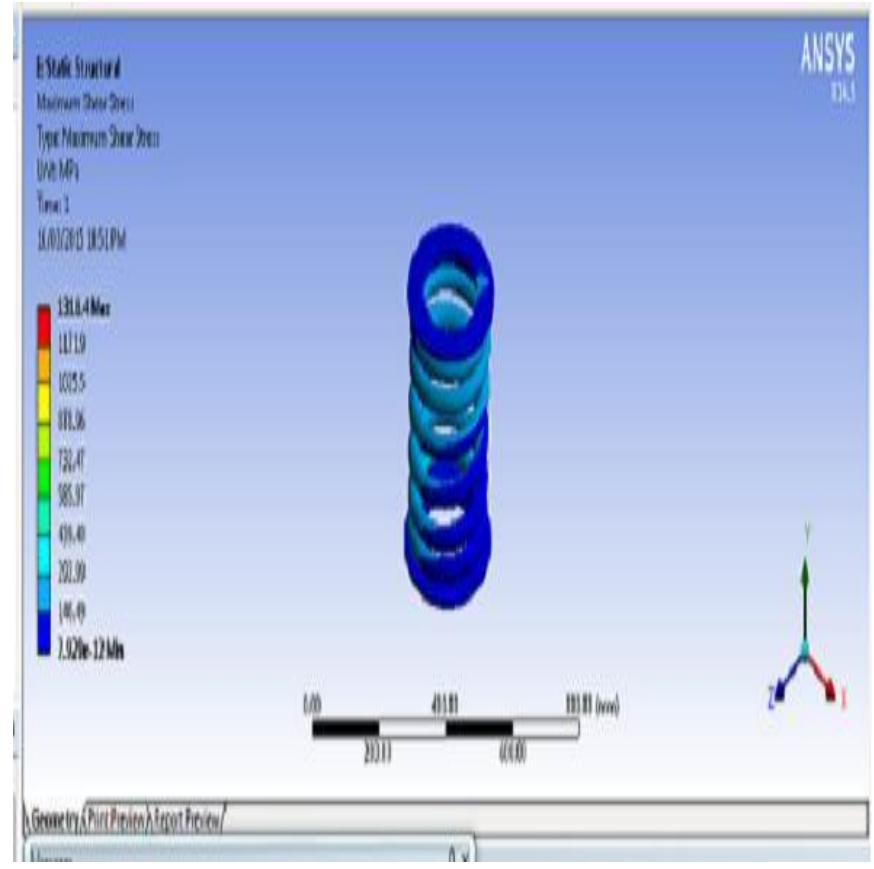

Fig 12 maximum shear stress $=1318 \mathrm{~N} / \mathrm{mm} 2$

\section{RESULT}

The Analysis is carried out for axle box spring at various degree of curvature. From the results obtained it is clear that maximum shear stress occurred while moving on $9^{0}$ of banking angle. The results are shown in fig.8 and 9 respectively. Analytical results are compared with the FEA results in table 2 to check the modal correctness. From FE analysis it is found that maximum shear stress occurs is $1318 \mathrm{~N} / \mathrm{mm}^{2}$ which is very near to allowable shear stress it means that the stresses induced while moving on curved path are very high. While negotiating with this curvature, the axle box springs are subjected to lateral loading causing the highest moment and shear stresses at the top end of springs. Therefore the bending stress due to lateral loading may initiate a failure which is further enhance and aggregated because of stress concentration at the failure region and nature of loading and once there is significant development of this crack the shearing occurs almost instantaneously. As spring is subjected to fatigue loading the continuous application of forces results into failure

\section{CONCLUSION}

Spring behavior is observed under expected loads. From FE analysis it is clear that spring is enough sufficient to withstand the loads on straight path. However While travelling on the curved path the shear stress are nearer to allowable stress.. Based on the results it is concluded that to negotiate curved path a lateral damper must be used for absorbing lateral loads. For improvement of spring life it will be always better to use a damper rather than to spend money on the maintenance and replacement of spring.

\section{REFERENCES}

[1]. Maintenance Manual for BG coaches of ICF design.

[2]. Indian Railway Drawing codeASSY.DRGNO.WTAC3-0-1-301.

[3]. Indian Railway Drawing code-ASSY.DRGNO.WTAC$0-5-202$.

[4]. Indian Railway Drawing codeASSY.DRGNO.WTAC5-9-0-501.

[5]. Indian Railways Schedule of Dimensions $1676 \mathrm{~mm}$ Gauge(BG),Ministry of Railways ANSYS USER GUIDE.

[6]. Investigation on Reduction in Premature Failure of Locomotive Coil Springs, PG Student B. Praveen Kumar, Professor P. Sampath Rao, International Journal of Engineering Research \& Technology (IJERT) ISSN: 22780181. IJERTV3IS090209 .Vol. 3 Issue 9, September- 2014.

[7]. Failure Analysis of Inner Suspension Spring of Railway Engine: A Case Study Manoj A. Kumbhalkar, Prof. Y. L. Yenarkar and Mr. A. K. Grover. Proc. of Int. Conf. on Advances in Robotic, Mechanical Engineering and Design 2011

\section{BIOGRAPHIES}

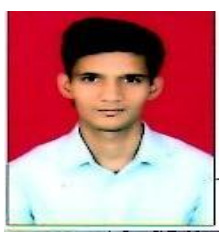

Rohan P.Joshi is a student of B.E. pursuing mechanical engineering degree from SAVITRIBAI PHULE PUNE university.

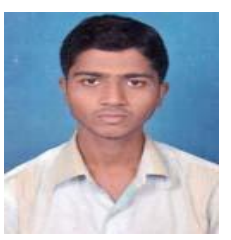

Sachin Chaudhari is a student of B.E. pursuing mechanical engineering degree from SAVITRIBAI PHULE PUNE university.

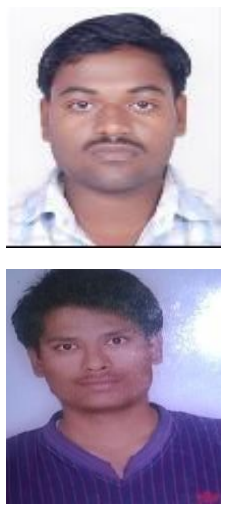

Dhanraj Choudhari is a student of B.E. pursuing mechanical engineering degree from SAVITRIBAI PHULE PUNE university

Pratik Chaugule is a student of B.E. pursuing mechanical engineering degree from SAVITRIBAI PHULE PUNE university. 